Article

\title{
Structure-Antifouling Activity Relationship and Molecular Targets of Bio-Inspired(thio)xanthones
}

\author{
Joana R. Almeida ${ }^{1}{ }^{(0)}$, Andreia Palmeira ${ }^{1,2}$, Alexandre Campos ${ }^{1}$, Isabel Cunha ${ }^{1}{ }^{(\mathbb{C},}$ \\ Micaela Freitas ${ }^{1,3,4} \mathbb{D}^{\mathbb{D}}$, Aldo Barreiro Felpeto ${ }^{1}$, Maria V. Turkina ${ }^{5}$, Vitor Vasconcelos ${ }^{1,3} \mathbb{E}^{\mathbb{D}}$, \\ Madalena Pinto ${ }^{1,2}$ (D), Marta Correia-da-Silva ${ }^{1,2, *(D)}$ and Emília Sousa ${ }^{1,2}$ (D) \\ 1 CIIMAR/CIMAR - Interdisciplinary Centre of Marine and Environmental Research, University of Porto, \\ Avenida General Norton de Matos, 4450-208 Matosinhos, Portugal; joana.reis.almeida@gmail.com (J.R.A.); \\ andreiapalmeira@gmail.com (A.P.); amoclclix@gmail.com (A.C.); isabel.cunha@ciimar.up.pt (I.C.); \\ Micaela.Faria@unige.ch (M.F.); aldo.barreiro@gmail.com (A.B.F.); vmvascon@fc.up.pt (V.V.); \\ madalena@ff.up.pt (M.P.); esousa@ff.up.pt (E.S.) \\ 2 Laboratory of Organic and Pharmaceutical Chemistry, Department of Chemical Sciences, \\ Faculty of Pharmacy, University of Porto, Rua Jorge Viterbo Ferreira, 228, 4050-313 Porto, Portugal \\ 3 Department of Biology, Faculty of Sciences, University of Porto, Rua do Campo Alegre, \\ P 4069-007 Porto, Portugal \\ 4 ISPSO-Institut des Sciences Pharmaceutiques de Suisse Occidentale, University of Geneva, \\ 1205 Geneva, Switzerland \\ 5 Department of Biomedical and Clinical Sciences, Linköping University, SE-581 85 Linköping, Sweden; \\ maria.turkina@liu.se \\ * Correspondence: m_correiadasilva@ff.up.pt
}

Received: 15 June 2020; Accepted: 27 July 2020; Published: 30 July 2020

check for updates

\begin{abstract}
The development of alternative ecological and effective antifouling technologies is still challenging. Synthesis of nature-inspired compounds has been exploited, given the potential to assure commercial supplies of potential ecofriendly antifouling agents. In this direction, the antifouling activity of a series of nineteen synthetic small molecules, with chemical similarities with natural products, were exploited in this work. Six $(4,5,7,10,15$ and 17) of the tested xanthones showed in vivo activity toward the settlement of Mytilus galloprovincialis larvae $\left(\mathrm{EC}_{50}: 3.53-28.60 \mu \mathrm{M}\right)$ and low toxicity to this macrofouling species ( $\mathrm{LC}_{50}>500 \mu \mathrm{M}$ and $\left.\mathrm{LC}_{50} / \mathrm{EC}_{50}: 17.42-141.64\right)$, and two of them (7 and 10) showed no general marine ecotoxicity ( $<10 \%$ of Artemia salina mortality) after $48 \mathrm{~h}$ of exposure. Regarding the mechanism of action in mussel larvae, the best performance compounds 4 and $\mathbf{5}$ might be acting by the inhibition of acetylcholinesterase activity (in vitro and in silico studies), while 7 and 10 showed specific targets (proteomic studies) directly related with the mussel adhesive structure (byssal threads), given by the alterations in the expression of Mytilus collagen proteins (PreCols) and proximal thread proteins (TMPs). A quantitative structure-activity relationship (QSAR) model was built with predictive capacity to enable speeding the design of new potential active compounds.
\end{abstract}

Keywords: xanthones; chemical synthesis; antifouling activity; invertebrates; molecular targets

\section{Introduction}

Biofouling is the temporary or permanent adhesion of organisms on water submerged man-made surfaces. It starts with the adsorption of a film of molecules and particles a few minutes after immersion, followed by the adhesion of bacteria, cyanobacteria, unicellular algae, and protozoa that form biofilms (microfouling) [1]. These organisms release biochemical cues that transmit specific information to the environment [2]. Such cues reach conspecifics and also organisms of other species, influencing the settlement, and metamorphosis of specific macrofouling species [3]. 
Maritime industries make large investments worldwide to control biofouling, which constitute an economic burden for shipping and aquaculture [4], and also to non-maritime industries such as paper manufacturing, food processing, underwater construction, power plants, and others. On the other hand, environmental problems are also associated with biofouling as the introduction of invasive species via vessels and maritime platforms promotes unbalances on local marine communities and contributes to loss of marine biodiversity [5].

The most common strategy being applied to combat biofouling is the use of antifouling coatings based on effective but somehow toxic active principles that need to be replaced [6,7], and environmentally benign alternatives are needed.

Natural alternatives including primary or secondary metabolites from a multitude of species have been found to inhibit the settlement of different biofouling species [8-11], particularly polyketide-related compounds [9]. Xanthone polyketide-derived compounds represent a class of marine natural compounds with interesting biological effects. Their interesting structural scaffold and the significant biological activities has led to the description of xanthones as "privileged structures" [12]. Several members were found to have antimicrobial activity and weak toxicity to brine shrimp (Artemia salina) [13]. Two new xanthone derivatives isolated from a coral-derived Aspergillus sp. were identified as having antifouling activities against Balanus amphitrite $\left(\mathrm{EC}_{50}<0.39 \mu \mathrm{M}\right)$ [14]. More recently, a xanthone isolated from a marine-derived fungus Aspergillus terreus was also found to be a potent antifoulant [15]. Nonetheless, little information on structure-antifouling activity relationship and ultimately on the mechanism of action of polyketide-related compounds, namely xanthones, is available [16,17].

Based on the above, and as a part of our efforts to discover innovative antifoulants inspired in natural products [18-20], a library of 19 synthetic xanthones was investigated for their antifouling potential (Figure 1).

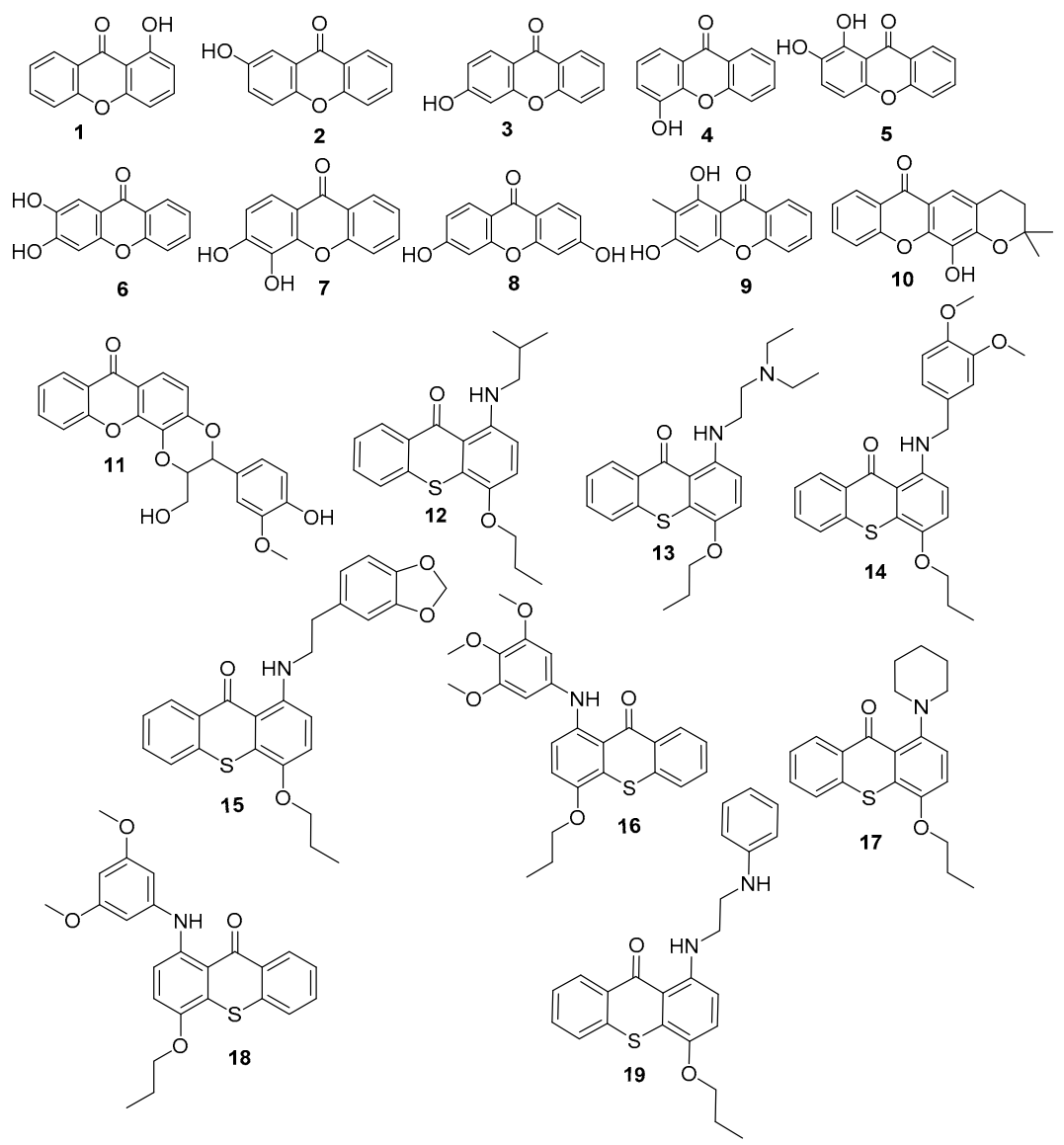

Figure 1. Library of xanthones investigated for antifouling activity. 
The anti-settlement activity toward the macrofouling species Mytilus galloprovincialis was evaluated in vivo and the subjacent mechanism of action of the most promising compounds was pursued by the potential modulation of selected enzymes with a role in adhesive processes (acetylcholinesterases (AChE) and tyrosinase (Tyr)) and by the differential analysis of the proteome of M. galloprovoincialis plantigrade larvae after exposure. In silico studies were also performed to disclose a quantitative structure-activity relationship (QSAR). Artemia ecotoxicity bioassay was performed to assess general marine ecotoxicity of antifouling candidates.

\section{Materials and Methods}

\subsection{Chemical Syntheses}

Melting points were obtained in a Köfler microscope (Wagner and Munz, Munich, Germany) and are uncorrected. IR spectra were recorded on a Nicolet iS10 FTIR spectrometer (ThermoScientific, ThermalSciecntific, MA, USA) in KBr microplates. ${ }^{1} \mathrm{H}$ NMR spectra were taken in DMSO- $\mathrm{d}_{6}$ at room temperature, on Bruker DRX 300 instrument. Chemical shifts are expressed in $\delta$ (ppm) values relative to TMS. The following 19 xanthone derivatives were synthesized according to previously described procedures [21-24]: 1-hydroxy- (1), 2-hydroxy-(2), 3-hydroxy-(3), 4-hydroxy-(4), 1,2-dihydroxy-(5), 2,3-dihydroxy-(6), 3,4-dihydroxy-(7), 3,6-dihydroxy-(8), 1,3-dihydroxy-2-methyl-(9), 4-dihydro-12-hydroxy-2,2-dimethyl-2H,6H-pyrano [3,2-b]xanthone (10), 2,3-dihydro-3-(4-hydroxy-3-methoxyphenyl)-2-(hydroxymethyl)-7H-1,4-dioxino[2,3-c]-(11). The synthesis of the following thioxanthone derivatives was performed according to described procedures [25]: 1-(Isobutylamino)-4-propoxy-9H-thioxanthen-9-one (12), 1-((2(diethylamino)ethyl)amino)-4-propoxy-9H-thioxanthen-9-one (13), 1-[(3,4-dimethoxybenzyl)amino]4-propoxy-9H-thioxanthen-9-one (14), 1-[11]-4-propoxy-9H-thioxanthen-9-one (15), 1-[(3,4,5trimethoxyphenyl)amino]-4-propoxy-9H-thioxanthen-9-one (16), 1-(piperidin-1-yl)-4-propoxy-9Hthioxanthen-9-one (17), 1-[(3,5-dimethoxyphenyl)amino]-4- propoxy-9H-thioxanthen-9-one (18), and 1-[2-(phenylamino)ethyl]amino]-4-propoxy-9H-thioxanthen-9-one (19). The investigated compounds presented purity $>95 \%$ by HPLC-DAD.

\subsection{Antifouling Screening}

\subsubsection{M. galloprovincialis Larvae Anti-Settlement Bioassays}

The 19 xanthone derivatives were screened for anti-settlement activity toward M. galloprovincialis plantigrade larvae. Samples of $M$. galloprovincialis juveniles were collected from mussel beds during low tides in the intertidal zone of Memória beach, Matosinhos, Portugal (41 $\left.13^{\prime} 59^{\prime \prime} \mathrm{N} ; 8^{\circ} 43^{\prime} 28^{\prime \prime} \mathrm{W}\right)$. Mussel plantigrade larvae (0.5-2 mm) were sorted in a binocular magnifier (Olympus SZX2-ILLT, Tokyo, Japan) and kept in filtered seawater until bioassays preparation. Mussel plantigrades exhibiting foot exploring behavior were selected for the xanthone derivatives screening bioassay at $50 \mu \mathrm{M}$ performed in 24-well microplates for $15 \mathrm{~h}$, in the dark at $18 \pm 1^{\circ} \mathrm{C}$, following Almeida et al. (2015) [26]. Five competent larvae were included per well and four well replicates per condition. Stock solutions (50 mM) in DMSO were used to prepare test media in filtered seawater $(0.1 \%)$. Negative and positive controls were used, namely DMSO $(0.1 \%)$ and $\mathrm{CuSO}_{4}(5 \mu \mathrm{M})$ as an efficient antifouling agent. After exposure, the anti-settlement bioactivity was determined by the observation of efficiently attached plantigrade larvae considering the existence/absence of produced byssal threads for each test condition. Compounds producing more than $50 \%$ of settlement inhibition at $50 \mu \mathrm{M}$ were selected for antifouling effectiveness $\left(\mathrm{EC}_{50}\right)$ and toxicity ( $\mathrm{LC}_{50}$ and therapeutic index) bioassays, according to previously validated experimental conditions.

\subsubsection{Quantitative Structure-Activity Relationship Model}

Nineteen (thio)xanthones were used to construct a QSAR model using the biological data obtained from the in vitro antifouling activity studies, measured as $\log$ (100/\%attachment). Antifouling activity 
was selected as dependent variable in the QSAR analysis. The 19 molecules were randomly distributed into a training set (15 molecules) and a test set (4 molecules). CODESSA 2.7.10 (CompuDrug, University of Florida, Gainesville, FL, USA) was used to calculate hundreds of constitutional, topological, geometrical, electrostatic, quantum-chemical, and thermodynamical molecular descriptors. The heuristic multilinear regression protocol was used to execute a thorough quest for the best multilinear correlations with the descriptors of the training set. The 2D-QSAR model with the best correlation coefficient $\left(\mathrm{R}^{2}\right)$, F-test $(\mathrm{F})$, and standard error (s) was chosen. The final model was farther validated using the test set and the leave-one-out cross validation.

\subsection{Antifouling Mechanism of Action}

\subsubsection{In Vitro Determination of Acetylcholinesterase (AChE) Inhibition Activity}

AChE inhibition was evaluated as a neurotransmission biomarker for the 19 compounds using Electrophorus electric AChE Type V-S (SIGMA C2888, E.C. 3.1.1.7), according to Ellman et al. (1961) [27] and modified by Almeida et al. (2015) [26]. Briefly, $250 \mu \mathrm{L}$ of the reaction solution containing $30 \mathrm{~mL}$ of phosphate buffer, $1 \mathrm{~mL}$ of the reagent dithiobisnitrobenzoate (DTNB) at $10 \mathrm{mM}$ (acid dithiobisnitrobenzoate and sodium hydrogen carbonate in phosphate buffer), and $200 \mu \mathrm{L}$ of acetylcholine iodide $0.075 \mathrm{M}$ was added to $50 \mu \mathrm{L}$ of pure $\mathrm{AChE}\left(0.25 \mathrm{U} \cdot \mathrm{mL}^{-1}\right)$ and each test compound at final concentration of $30 \mu \mathrm{g} \mathrm{mL} \mathrm{m}^{-1}$ in quadruplicate. AChE activity was followed at $412 \mathrm{~nm}$ during $5 \mathrm{~min}$ at $25^{\circ} \mathrm{C}$. Negative and positive controls were included, namely ultra-pure water and eserine $(20 \mathrm{mM})$, respectively, and a blank containing $50 \mu \mathrm{L}$ of phosphate buffer.

\subsubsection{In Vitro Determination of Tyrosinase Inhibition Activity}

Tyrosinase inhibition assays were conducted using Agaricus bisporus tyrosinase (EC 1.14.18.1) according to Adhikari et al. [28] with appropriate adaptations. The enzymatic reaction follows the catalytic conversion of L-Dopa to dopaquinone and the formation of dopachrome by measuring the absorbance at $475 \mathrm{~nm}$. Briefly, $50 \mu \mathrm{L}$ of tyrosinase $\left(25 \mathrm{U}_{\mathrm{mL}}^{-1}\right)$ in $50 \mathrm{mM}$ phosphate buffer $\mathrm{pH} 6.5$, adding the defined concentration of compounds in DMSO. The enzymatic activity was initiated by L-dopa (25 mM). Kojic acid was used as positive control and DMSO as negative control.

\subsubsection{Docking Studies for AChE Activity}

Docking studies were conducted by modulation of Electrophorus electric AChE and Agaricus bisporus tyrosinase. Crystal structure of Electrophorus electric AChE (PDB code: 1C2O) and of Agaricus bisporus tyrosinase (PDB code: 2Y9X), downloaded from the protein databank (PDB), were used for the docking studies. Structure files of two known AChE inhibitors described as antifouling agents, pulmonarins A and B [29], and seven known tyrosinase inhibitors also described as antifouling agents, PLOS12-18 [30], were drawn and minimized using the chemical structure drawing tool Hyperchem 7.5 (Hypercube). Autodock Vina (Molecular Graphics Lab, The Scripps Research Institute, San Diego, CA, USA). was employed for the docking study, using the following parameters: exhaustiveness $=8$; grid box $=25.0 \times 25.0 \times 25.0 \AA$, surrounding the acetylcholine active site and peripheral anionic site (PAS); grid box $=15.0 \times 20.0 \times 25.0 \AA$, surrounding the crystallographic ligand binding site of tyrosinase. Top 9 poses were found for each input molecule. The lowest docking score poses that fit the active site triad (Ser-203, His-447, and Glu-334) and PAS of AChE, and active site of tyrosinase containing two copper atoms coordinated with histidines were chosen for further analysis of binding mechanism and visual inspection using PyMol 1.3 (Schrödinger, New York, NY, USA).

\subsubsection{Antifouling Molecular Targets Assessment in M. galloprovincialis by Differential} Proteome Analysis

M. galloprovincialis plantigrade larvae proteome was analyzed according to experimental procedures described in Campos et al. (2016) [31]. Briefly, the whole protein content of M. galloprovincialis 
plantigrades (10 larvae per replicate) was solubilized in lysis buffer with 2\% (w/v) SDS, $100 \mathrm{mM}$ Tris-HCl, $0.1 \mathrm{M}$ DTT, and protease inhibitor at $\mathrm{pH}$ 7.6. Proteins were subsequently digested using the filter aided sample preparation (FASP) [32]. The obtained peptides were analyzed by nano-LC coupled to a hybrid Ion trap-Orbitrap mass spectrometer (LTQ Orbitrap Velos Pro, Thermo Scientific, Waltham, EUA). Full scans were performed at 30,000 resolution with scan ranges of 380-2000 $\mathrm{m} / \mathrm{z}$ and the top 20 most intense ions isolated and fragmented. Collision-induced fragmentation (CID) was used to fragment precursor ions. LTQ raw data were first processed in Proteome Discoverer software (version 1.4, Thermo Scientific, Waltham, EUA) and identifications achieved using X!Tandem algorithm in the Scaffold program (version Scaffold 4.3.4, Proteome Software, Portland, OR, USA) and using a composite database built with genomic and transcriptomic information from M. gallopronvicialis (46,791 sequences) and Bathymodiolus azoricus (33,464 sequences) [31]. Protein quantitative analysis was determined using normalized spectral abundance factors (NSAFs) in Scaffold program and employing non-parametric statistics $(p<0.05)$.

\subsection{Ecotoxicity Assessment}

Ecotoxicity to non-target species was assessed using the brine shrimp (Artemia salina) lethality test standard protocol $[18,33]$. Artemia cysts were cultivated and newly hatched nauplii I were used for the exposure to the most promising antifouling compounds at 50 and $25 \mu \mathrm{M}$. The bioassay was performed in 96-well microplates with eight replicates per condition and 15-20 nauplii per well. Positive $\left(\mathrm{K}_{2} \mathrm{Cr}_{2} \mathrm{O}_{7}\right.$ at $13.6 \mu \mathrm{M}$ ) and negative (DMSO) controls were included. After $48 \mathrm{~h}$ of exposure, the percentage of nauplii mortality was determined.

\subsection{Data Analysis}

Data from the anti-settlement bioassays, namely the semi-maximum response concentration that inhibited $50 \%$ of larval settlement $\left(\mathrm{EC}_{50}\right)$ for each bioactive compound was assessed using Probit regression analysis (Log10) with 95\% lower and upper confidence limits [95\% LCL;UCL]. Therapeutic ratios $\left(\mathrm{LC}_{50} / \mathrm{EC}_{50}\right)$ were used to evaluate the effectiveness versus toxicity of bioactive compounds. For the differential proteome analysis, non-parametric Kruskall-Wallis (KW) and Mann Whitney (MW) tests were utilized to report protein abundance differences between treatments in MultiExperiment Viewer (MeV) version 4.9 (The Institute for Genomic Research (TIGR), La Jolla, CA, USA) at a confidence level of $95 \%$ [34]. The hierarchical clustering of proteins was made using Pearson correlation and average linkage method.

\section{Results and Discussion}

\subsection{Antifouling Bioactivity}

From the series of compounds tested (1-19), which include 11 xanthones (oxygenated, prenylated, lignoids) and 8 aminated thioxanthones, significant anti-settlement responses ( $\geq 50 \%$ of settlement inhibition) were identified in the initial screening bioassay in the presence of six compounds, namely 4 $(70.0 \pm 12.9 \%) ; \mathbf{5}(70.0 \pm 12.9 \%) ; \mathbf{7}(65.0 \pm 17.1 \%) ; \mathbf{1 0}$ (75 $\pm 9.6 \%) ; \mathbf{1 5}(71.2 \pm 10.9 \%) ;$ and $\mathbf{1 7}(71.7 \pm 5.0 \%)$. These compounds were selected for dose-response studies.

Dose-response bioassays confirmed the antifouling bioactivity toward mussel plantigrade larvae settlement, being the most effective the compounds $17\left(\mathrm{EC}_{50}=3.53 \mu \mathrm{M}\right), \mathbf{1 0}\left(\mathrm{EC}_{50}=4.60 \mu \mathrm{M}\right)$, and $7\left(\mathrm{EC}_{50}=11.53 \mu \mathrm{M}\right)($ Figure 2; Table 1). 
. $405 \wedge 7 \square 10 \bullet 15 \bullet 17$

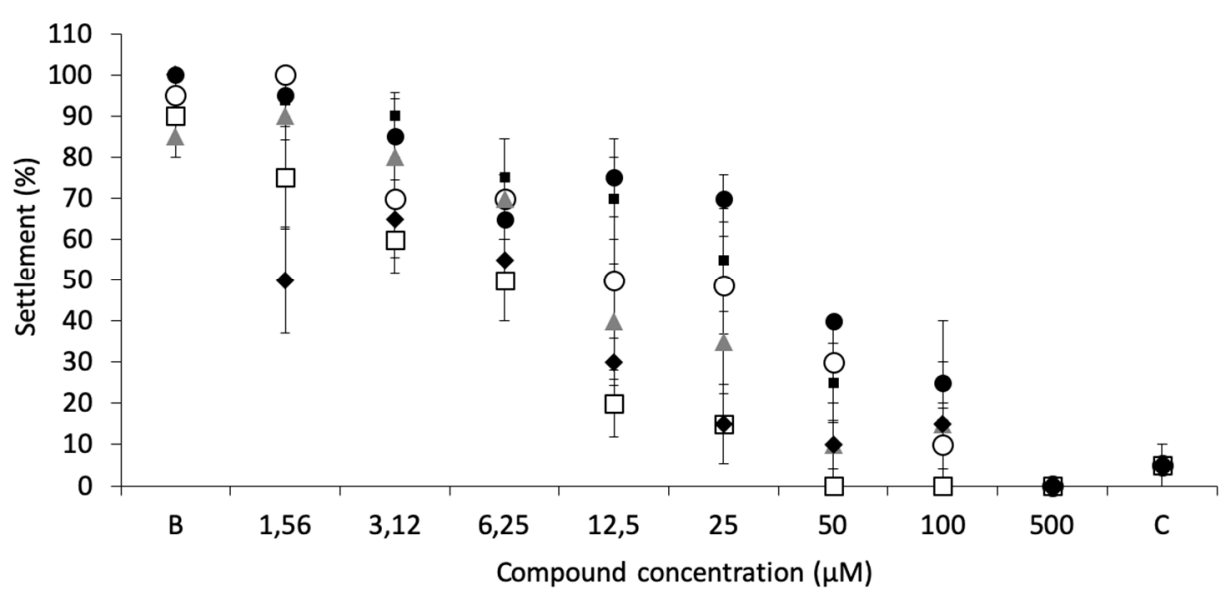

Figure 2. Dose-response of anti-settlement activity of the promising antifouling compounds 4, 5, 7, 10, 15, and 17 toward plantigrades of the mussel M. galloprovincialis. B: negative control; C: $\mathrm{CuSO}_{4} 5 \mu \mathrm{M}$ as positive control.

Table 1. Antifouling effectiveness versus toxicity of compounds toward the anti-settlement of mussel plantigrades.

\begin{tabular}{cccc}
\hline Compound & EC $_{\mathbf{5 0}}\left(\boldsymbol{\mu M} ; \boldsymbol{\mu g} \cdot \mathbf{m L}^{-\mathbf{1}}\right)$ & $\mathbf{L C}_{\mathbf{5 0}}(\boldsymbol{\mu M})$ & LC $_{\mathbf{5 0}} / \mathrm{EC}_{\mathbf{5 0}}$ \\
\hline $\mathbf{4}$ & $21.48(95 \%$ CI: $15.37-30.79) ; 4.55$ & $>500$ & $>23.28$ \\
$\mathbf{5}$ & $15.46(95 \%$ CI: $10.29-23.30) ; 3.52$ & $>500$ & $>32.34$ \\
$\mathbf{7}$ & $11.53(95 \%$ CI: $7.01-18.39) ; 2.63$ & $>500$ & $>43.37$ \\
$\mathbf{1 0}$ & $4.60(95 \%$ CI: $3.21-6.20) ; 1.36$ & $>500$ & $>108.70$ \\
$\mathbf{1 5}$ & $28.60(95 \%$ CI: $19.58-43.97) ; 12.40$ & $>500$ & $>17.48$ \\
$\mathbf{1 7}$ & $3.53(95 \%$ CI: $1.29-6.47) ; 1.25$ & $>500$ & $>141.64$ \\
\hline
\end{tabular}

$\mathrm{EC}_{50}$, minimum concentration that inhibited $50 \%$ of larval settlement; $\mathrm{LC}_{50}$ the median lethal dose; $\mathrm{LC}_{50} / \mathrm{EC}_{50}$, therapeutic ratio. Note: reference values for $\mathrm{EC}_{50}<25 \mu \mathrm{g} \cdot \mathrm{mL}^{-1}$ (U.S. Navy program) and therapeutic ratio $\left(\mathrm{LC}_{50} / \mathrm{EC}_{50}\right)$ higher than 15.

Regarding toxicity to mussel plantigrade larvae, only compounds $\mathbf{1 0}$ and $\mathbf{1 7}$ showed some mortality at high concentrations, $15 \%$ at $100 \mu \mathrm{M}$ and $17 \%$ at $500 \mu \mathrm{M}$, respectively, a much lower mortality when compared to the commercial eco-friendly active ingredient ECONEA ( $50 \%$ at $108 \mu \mathrm{M})$, in the same bioassay conditions [20].

No mortality was observed for all the other promising compounds at any of the concentrations tested. Therapeutic ratios $\left(\mathrm{LC}_{50} / \mathrm{EC}_{50}\right)$ were higher than 15 for all the compounds, the most promising levels being related to compounds 7, 10, and $\mathbf{1 7}$ (Table 1). These results highlighted the importance of a hydroxyl substituent at position 4 of the xanthonic scaffold.

\subsection{Structure-Activity Relationship (QSAR) Studies}

As quantitative structure-activity relationship (QSAR) studies have been employed during decades to find relevant small molecules properties and to forecast different biological activities [35], a QSAR model was built to highlight the descriptors important for the anti-macrofouling activity of these derivatives. In this work, a 2D-QSAR model was built using Comprehensive Descriptors for Structural and Statistical Analysis (CODESSA) software package (CompuDrug, CODESSA software version 2.7.2, University of Florida, Gainesville, FL, USA). A huge number of constitutional, topological, geometrical, electrostatic, and quantum-chemical descriptors are automatically generated. The heuristic method continues with a preselection of descriptors by erasing those that are not available for each structure, that have a small variation in magnitude for all structures, that are correlated pairwise, and that have 
no statistical significance. The heuristic method is a quick and very appropriate method for searching the best group of descriptors.

The correlation coefficient $\left(R^{2}\right)$, standard error (s), and Fisher's value (F) were used to evaluate the validity of regression equation. As the training set was composed of 15 molecules, 3 descriptors were used to build the QSAR model. The multilinear regression analysis using the Heuristic method for 15 compounds in the three-parameter model is given in Figure 3.

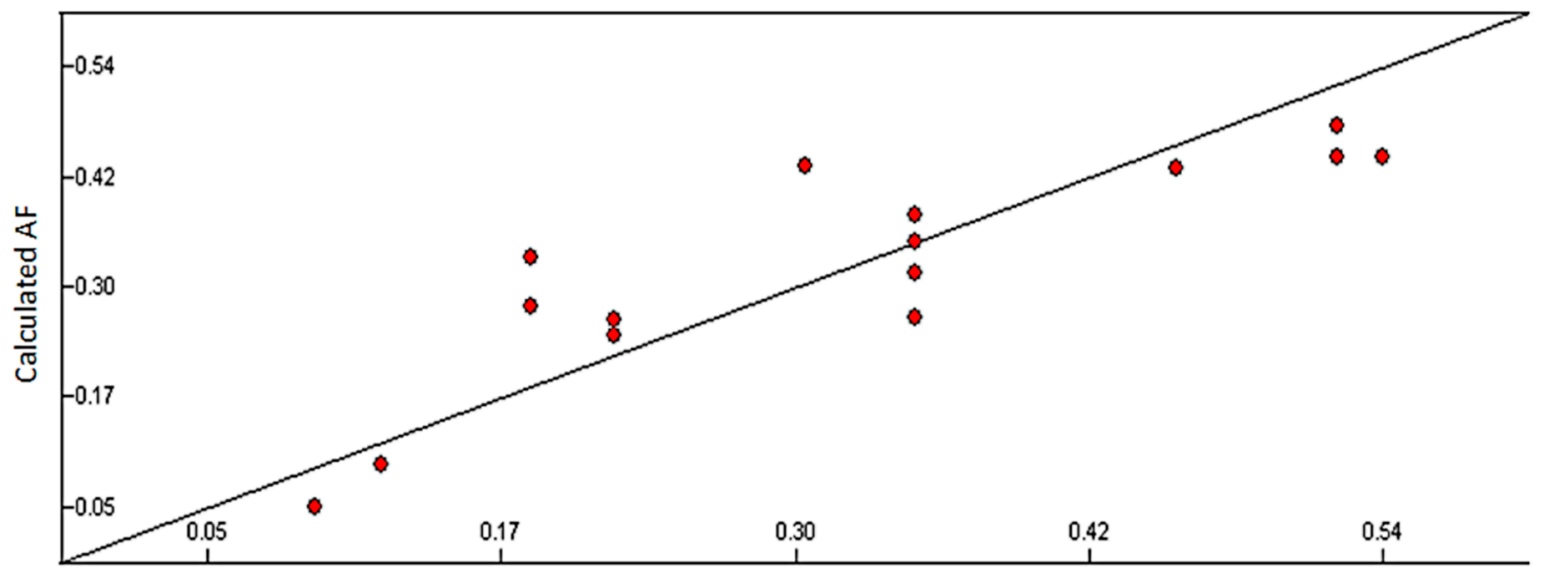

Experimental AF

\begin{tabular}{rrrrl}
\hline $\mathrm{Nr}$ & $\mathrm{X}$ & $\mathrm{DX}$ & t-test & \multicolumn{1}{c}{ Name of the descriptor } \\
& & & \\
0 & -1.1371 & 0.4718 & -2.4099 & Intercept \\
1 & 2.1060 & 0.4798 & 4.3888 & Average Bonding Information content (order 2) \\
2 & -0.0023 & 0.0007 & -2.9663 & PNSA-1 Partial negative surface area \\
3 & 0.0898 & 0.0554 & 1.6176 & Topographicelectronic index (all bonds) \\
\hline
\end{tabular}

Figure 3. Quantitative structure-activity relationship (QSAR) model obtained with the heuristic method for 15 xanthones with the CODESSA software $\left(R^{2}=0.7335, F=10.09\right.$, and $\left.s=0.0085\right) . X, \Delta X$ and $t$-test are the regression coefficient of the linear model, standard errors of the regression coefficient, and the $t$ significance coefficient of the determination, respectively. AF $=$ antifouling activity.

The best training model had a quality $\left(\mathrm{R}^{2}\right)$ of 0.7335 , Fisher value of 10.09 , and $S$ of 0.0085 , which is an evidence that the suggested model has suitable statistical stability and validity. The $\mathrm{R}^{2}$, a relative measure of quality of the model, is greater than 0.7 , which is a signal of an appropriate fit to the regression line. Accordingly, it represents more than $70 \%$ of the total variance in antifouling activity shown by the test compounds. The F-test represents the ratio of the variance of the model and the variance due to the error in the regression. The QSAR model is statistically significant at the $95 \%$ level as revealed by the F-test values which are higher than the tabulated values (3.59). Standard deviation $\mathrm{s}$ is a measurement of the quality of the fit and should have a low value (0.0085) for the regression to be significant. The leave-one-out cross-validated $\mathrm{R}^{2}\left(\mathrm{Q}^{2}\right)$ assesses how the results of the QSAR model will generalize to an independent data set. $Q^{2}(0.57)$ is smaller than the overall $R^{2}(0.73)$, but still the difference between $\mathrm{R}^{2}$ and $\mathrm{Q}^{2}$ is lower than 0.3 , which indicates that the model has suitable predictivity. External test set predictivity was also used to validate the model. The model was capable of predicting the growth inhibitory activity of an external test set with an average difference of 0.15 from the experimental results [36]. From everything before mentioned, it can be said that the QSAR model is relevant for the prediction of the antifouling activity of other compounds.

Average bonding information content (order 2), PNSA-1 partial negative surface area, and topographic electronic index (all bonds) are predicted as being involved in the antifouling activity of the tested compound (Figure 3). 
A graph vertex complexity index descriptor-average bonding information content (order 2) — is predicted as being the most relevant descriptor affecting positively the antifouling activity of the test compounds. It is a symmetry descriptor (neighborhood symmetry of second order) related to the number of bonds counting bond orders, which provides information on the complexity of the molecule [37-39].

The second most important descriptor is the partial negative surface area PNSA-1, which quantifies the actually available surface area portion provided by all negatively charged atoms [39].

The third most important descriptor is an electrostatic-related descriptor-topographic electronic index-that is calculated from the partial atomic charges and the inter-atomic distances between all the pairs of atoms in the molecule. This type of descriptor reflects how differences in size, shape, and constitution affect the electronic charge distribution and inter-atomic distances of the molecules [39].

In summary, the structure-activity relationship captured by the linear model indicates that the complexity of the molecule, the electronic charge distribution, and inter-atomic distances influence the antifouling activity.

\subsection{Insights on Antifouling Mode of Action}

\subsubsection{AChE Activity}

The potential of xanthone derivatives to inhibit AChE activity was evaluated for the 19 xanthones, as AChE has a metabolic role in the process of settlement of macrofouling organisms (Figure 4a) [26].

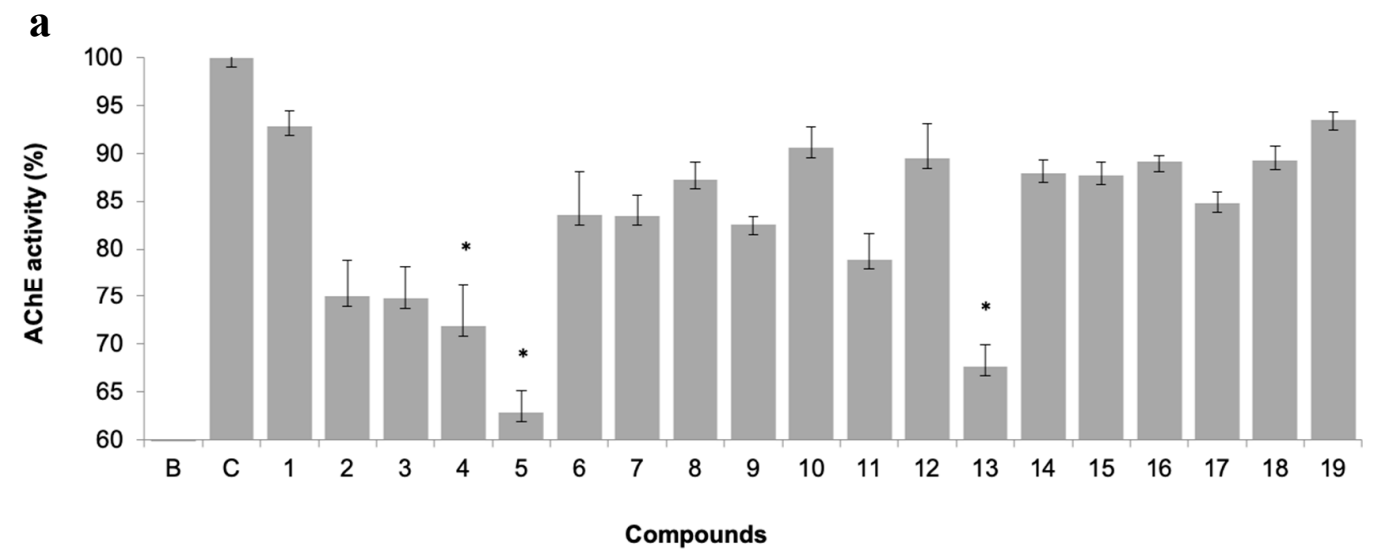

b

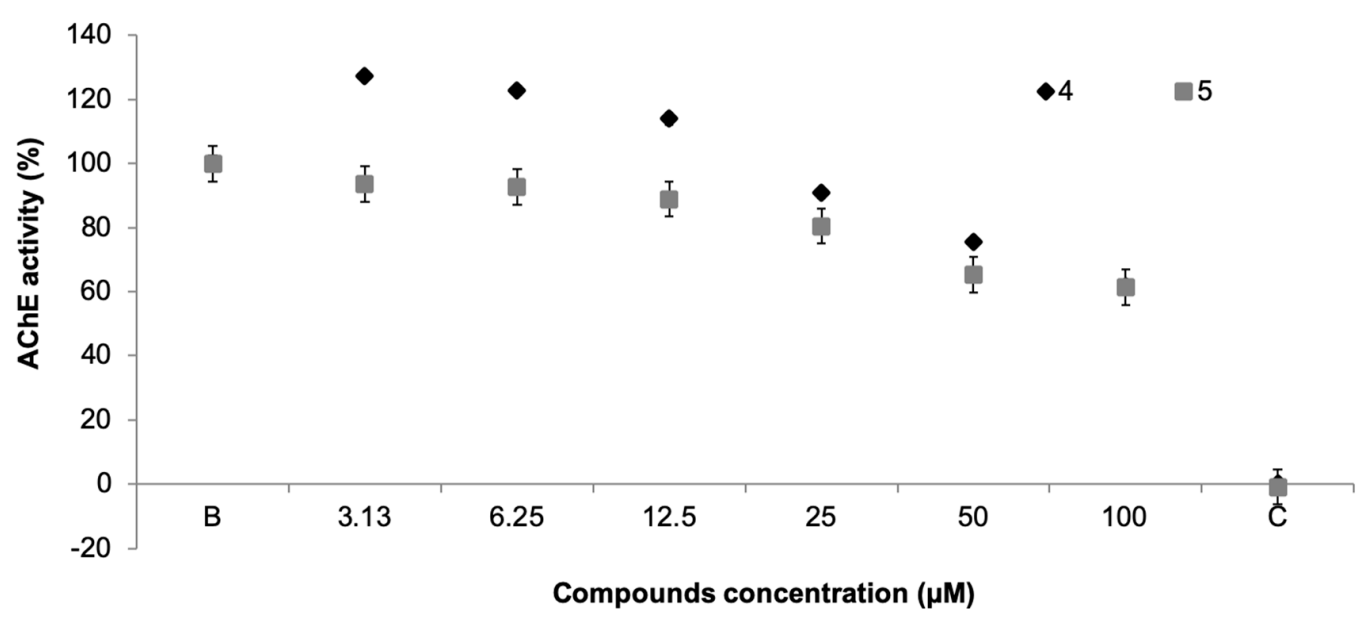

Figure 4. (a) Acetylcholinesterases (AChE) activity of 19 pure xanthones $(50 \mu \mathrm{M}) .{ }^{*}$ significant differences ( $p \leq 0.05$, Dunnett's test) compared to the negative control (B); eserine was used as positive control (C).

(b) Dose-response of AChE activity of selected xanthones 4 and 5. 
Three compounds showed AChE inhibition at $50 \mu \mathrm{M}$ when compared to control, namely the promising antifouling xanthones 4 and 5, which showed concentration-dependent modulation of AChE activity (Figure $4 \mathrm{~b}$ ). This inhibitory activity may be contributing to the antifouling activity of these two compounds.

\subsubsection{Docking Studies Regarding AChE Activity}

In order to understand the binding mode of the most promising molecules 4 and 5 to AChE, docking studies were performed. AChE is a serine hydrolase and the crystallographic structure reveals the presence of a narrow, long, and hydrophobic cavity (Figure 5). The active site of AChE comprises 2 subsites - the esteratic and anionic subsites. The esteratic subsite, where acetylcholine (ACh) is hydrolyzed to acetate and choline, contains the catalytic triad of three amino acids: Ser-203, His-447, and Glu-334, the lining of which contains mostly aromatic residues that form a narrow entrance to the catalytic Ser-203 [40]. The activation of Ser-203 allows the acylation between hydroxyl group of that residue and $\mathrm{ACh}$ oxygen. In the anionic site, the indole side chain of the conserved residue Trp86 makes a cation- $\pi$ interaction with the quaternary amino group of ACh. On the entrance of the active site, a peripherical anionic site (PAS) is composed of several aromatic residues (such as Tyr-72, Asp-74, Tyr-124, Trp-286), lining a hydrophobic region that traps ACh and transfers it to the deep catalytic site [41]. Distinctive inhibitors bind to the active center or to the PAS located at the rim of the gorge near the enzyme surface. Several studies have shown that some inhibitors of AChE bind at the catalytic site, acting as competitive inhibitors, while others can bind to PAS located at the rim of the active site gorge. PAS inhibitors inhibit catalysis by sterically blocking ligands from entering and leaving the active site gorge, and by allosterical alteration of the catalytic triad conformation [42]. Two antifouling compounds from Ascidian Synoicum described as competitive AChE inhibition with no antibiotic nor cytotoxic activity (pulmonarin A and B) [29] were used as positive controls in the in silico docking study. According to the docking results, pulmonarin A and B are able to bind active site


scores: $\left.\mathrm{A}_{(\mathrm{PAS})}=-5.5 \mathrm{kcal} . \mathrm{mol}^{-1} ; \mathrm{B}_{(\mathrm{PAS})}=-6.8 \mathrm{kcal}_{\mathrm{mol}} \mathrm{mol}^{-1}\right)$. Compound 4 formed a more stable complex (lower docking score) with AChE PAS (docking score: $\mathbf{4}_{(\mathrm{PAS})}=-8.5 \mathrm{kcal} . \mathrm{mol}^{-1}$ ) than positive controls pulmonarin $\mathrm{A}$ and $\mathrm{B}$ and only formed a more stable complex with AChE active site (docking score: $\mathbf{4}_{(\text {ACTIVE SITE) }}=-6.7{\left.\mathrm{kcal} . \mathrm{mol}^{-1}\right)}$ than pulmonarin A; compound 5 formed a more stable complex (lower docking score) with both AChE PAS and active site (docking score: $\mathbf{5}_{\text {(PAS) }}=-7.6 \mathrm{kcal}^{\mathrm{mol}}{ }^{-1}$; $5_{(\text {ACTIVE SITE })}=-8.2{\left.\mathrm{kcal} . \mathrm{mol}^{-1}\right)}$ than the positive controls pulmonarin A and $\mathrm{B}$.

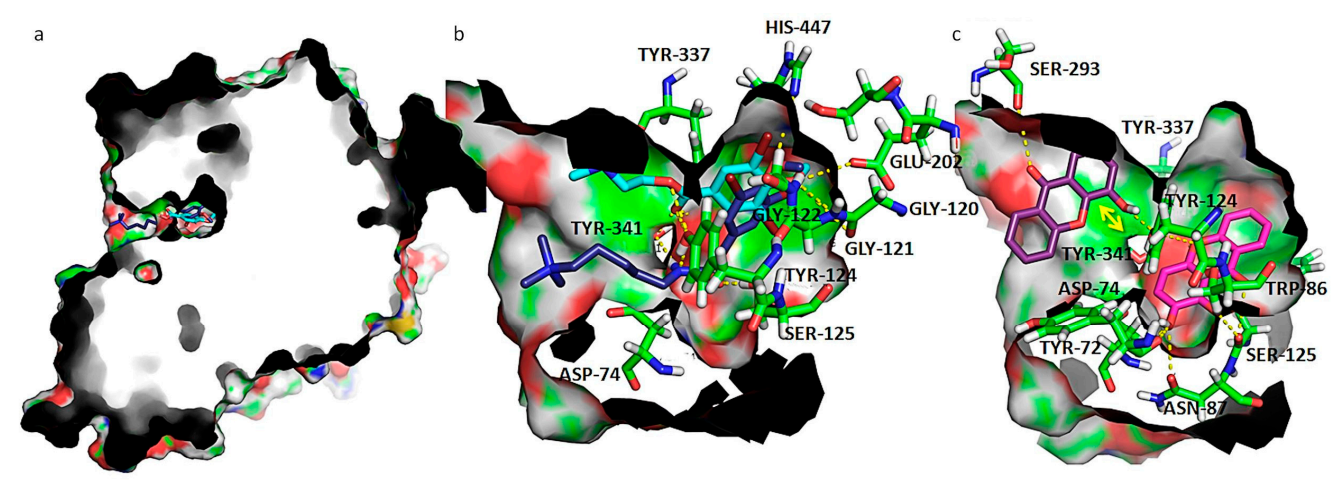

Figure 5. (a) Capped surface of AChE, showing the ACh binding pocket with AChE inhibitors pulmonarin A and B (blue sticks); (b) detailed view of known antifouling AChE inhibitors: pulmonarin A (light blue sticks) and pulmonarin B (dark blue sticks); (c) detailed view of test compounds 4 (purple sticks) and 5 (magenta sticks). Hydrogen interactions are represented with yellow broken line and stacking interactions with a double edge yellow arrow. Residues involved on those interactions are represented as green sticks and labeled. AChE is represented as solid surface, where carbon, hydrogen, oxygen, nitrogen, and sulfur are represented in green, grey, red, blue, and yellow, respectively. 
In order to understand the binding mode of the most promising molecules 4 and 5 to AChE, a careful examination of the most stable docking poses was performed and compared with controls (Figure 5).

The interactions between known inhibitors pulmonarin $A$ and $B$ and the enzyme are characterized by hydrogen bonds with residues Asp-74, Gly-120, Gly-121, Gly-122, Tyr-124, Ser-125, Glu-202, Tyr-337, Tyr-341, and His-447 (Figure 6a,b). It is described that ACh binds to Asp-74 at the peripheral site of human AChE as the first step in the catalytic pathway [43]; Gly-120, Gly-121, and Gly-122 are described as important to strengthen the interaction with ACh [44]. Tyr-124 is also shown to be involved in the hydrolysis of $\mathrm{ACh}$, carbamylation, phosphonylation, and oxime reactivation mechanisms, besides regulating the flow of substrates into the catalytic site from the gorge [45]. Ser-125 has already been described as being involved in hydrogen interactions with piperazine AChE inhibitors [46]. The acidic residues Asp-74 and Glu-202 create a dipole that allows the positively charged ACh to move down the gorge [47]. Amino acid residues Tyr-337 and Tyr-341 are involved in the binding of reversible AChE inhibitors Huperzine A [48] and tacrine [49] respectively. His-447 is a member of the catalytic triad, the ring of which is flipped to form a reactive Glu-334-His-447-oxime triad [50].

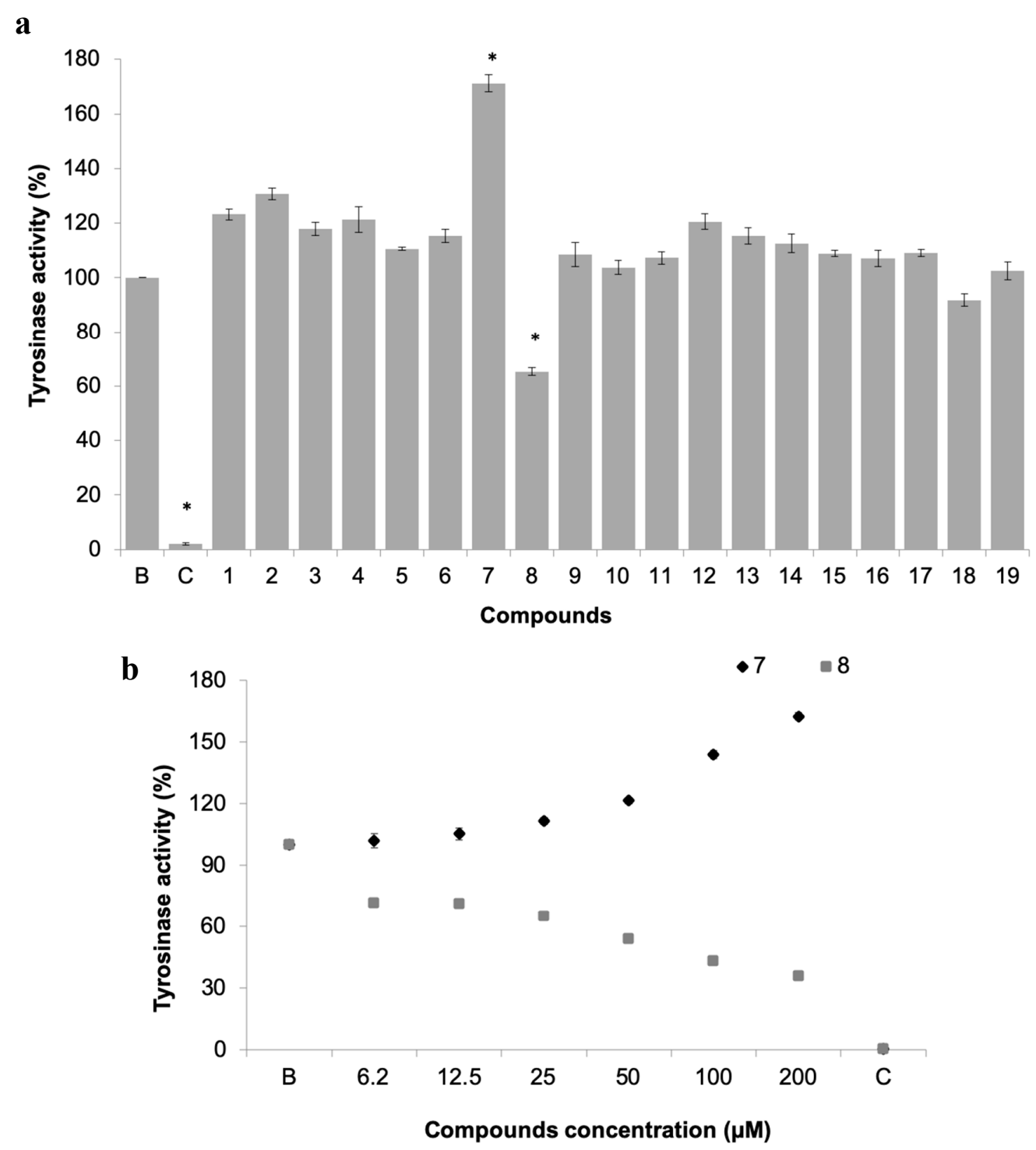

Figure 6. (a) Tyrosinase activity of 19 pure xanthones. ${ }^{*}$ significant differences ( $p \leq 0.05$, Dunnett's test) compared to the negative control (B); kojic acid was used as positive control (C). (b) Dose-response tyrosinase activity of selected compounds 7 and 8 . 
Compound 5 docked more stably at the bottom of the binding groove that forms a hydrophobic pocket base and that contains the catalytic Ser-203 (docking score of $-8.2 \mathrm{kcal}^{\mathrm{mol}}{ }^{-1}$ ) (Figure 5c), but a higher energy binding pose at PAS also exists (docking score of $-7.6 \mathrm{kcal}^{\mathrm{mol}}{ }^{-1}$ ). On the other hand, compound 4 binds preferably at PAS (Figure 5c), with a docking score of $-8.5 \mathrm{kcal}^{-\mathrm{mol}^{-1}}$, but binding in the narrow active groove is also possible (docking score of $-6.7 \mathrm{kcal}^{\mathrm{mol}} \mathrm{m}^{-1}$ ). As far as hydroxyl or methoxy xanthones are concerned, the narrower gorge in AChE results in a conformation where the xanthone scaffold packs against the aromatic hydrophobic portions of the side chain of Trp-86, establishing parallel $\pi-\pi$ interactions, as seen for compound 5 (Figure $5 \mathrm{c}$ ). Packing in this region is quite tight, and only the smallest substituents might be accommodated. Upon analysis of the interaction of compound 5 in AChE active site, hydrogen interactions with Tyr-72, Asp-74, Trp-86, Asn-87, Tyr-124, and Tyr-337 were stablished. The xanthonic moiety of 5 establishes near-parallel stacking of the planar tricyclic ring system with Trp-86 (Figure 5c). As far as compound 4 is concerned, which binds more stably at PAS, it establishes hydrogen interactions with Ser-293 and Tyr-124. The xanthonic moiety of 4 is positioned in a conformation that allows near-parallel stacking of the planar tricyclic ring system with Tyr-341.

All in all, docking results implied that the possible antifouling mechanisms of xanthonic derivatives may be attributed to the interactions between xanthone and AChE, such as hydrogen bonds, $\pi$-stacking, cation-dipole, hydrophobic, and van der Waals interactions.

\subsubsection{In Vitro Determination of Tyrosinase Activity}

The inhibition of this enzyme activity would affect the settlement and attachment ability of mussel larvae, as it has been described as an anti-settlement mode of action [51], however the tyrosinase/phenoxidase cascade pathways play an important role in different physiologically processes in invertebrates, including immune responses, sclerotization of the cuticle and wound healing. From the 19 compounds tested, two compounds were found to modulate tyrosinase activity (Figure 6a). While compound 8 was found to inhibit tyrosinase activity at $34 \%$ at $50 \mu \mathrm{M}$, the compound 7 , previously discover with anti-settlement activity against mussel larvae, was found to induce tyrosinase activity from 11.7 to $62.5 \%$ at 25 to $200 \mu \mathrm{M}$, respectively (Figure $6 \mathrm{~b}$ ). Considering this, the induction of tyrosinase activity by compound 7 might be related to accelerated immune responses facing exposure or to higher demand of inputs on the pathways related to the construction of cytoskeleton (adhesive apparatus). This last hypothesis is further supported by the results obtained by differentially expressed proteins in proteomic studies.

\subsubsection{Antifouling Targets by Proteomics}

As to provide additional molecular insights on the antifouling properties of selected compounds, the proteome of competent $M$. galloprovincialis plantigrade larvae in response to the three most potent compounds $(7,10$, and 17) was analyzed by label-free shotgun proteomics. Quantitative protein variations were surveyed employing statistics (non-parametric methods, KW and MW) and hierarchical clustering. Independent statistical tests were performed for each individual compound and results are summarized in Figure 7. Supplementary Tables S1 and S2 provide respectively, the complete information regarding the statistics of protein expression and the molecular functions of identified proteins.

Compound 7 was the one that induced more alterations in the mussel plantigrade larvae proteome, among the three antifouling compounds. In total, this compound at 12.5 and $50 \mu \mathrm{M}$ altered the abundances of 24 proteins (Figure 7, Supplementary Table S1), suggesting alterations in a large spectrum of both general and specialized cellular pathways. The differential proteins are involved in the production of energy (succinate dehydrogenase mitochondrial), cytoskeleton integrity, and vesicle-mediated transport (beta-actin, myosin heavy chain, F-actin-capping subunit beta, LIM and SH3 domain LASP, ras-like GTP-binding Rho1, ras-related protein O-krev, transitional endoplasmic reticulum ATPase), protein folding and chaperone functions (heat shock 90, T-complex 1 subunit theta, 
T-complex protein 1 subunit epsilon), carbohydrate metabolism (chitin deacetylase 9), amino acid metabolism (aspartate mitochondrial aminotransferase), cell redox homeostasis (alcohol dehydrogenase class-3, thioredoxin domain-containing protein 3, dihydrolipoyl dehydrogenase, mitochondrial), protein glycosylation (UDP-N-acetylhexosamine pyrophosphorylase), gene translation (60S ribosomal L23a), ERK1 and ERK2 mediated signal transduction (complement C1q 4), cellular ion homeostasis and membrane polarization (sodium/potassium-transporting ATPase subunit beta-3) and proteasome activity (proteasome subunit alpha type-3) (Figure 7 and Supplementary Table S2). The results evidence the cellular action of 7 particularly toward the functions of cytoskeleton, chaperone-mediated regulation of protein activity and cell redox status. Two putative collagen proteins, protein-2 collagen-like and precollagen $\mathrm{P}$ displayed contrasting patterns of abundance, being respectively above and below the control levels, in the groups exposed to 7. Mytilus collagen proteins (PreCols) are specific to the byssal threads and comprehend the main constituents of this adhesive structure. Several structural domains were identified in PreCols, which are thought to confer increased elasticity in areas of the protein subjected to more tension and bending [52]. Moreover, the byssal thread properties such as resistance to tension and shock absorber are essentially provided by these proteins. The inhibitory effects in adhesion of $\mathbf{7}$ may well be also associated with the change in the abundance of PreCols.

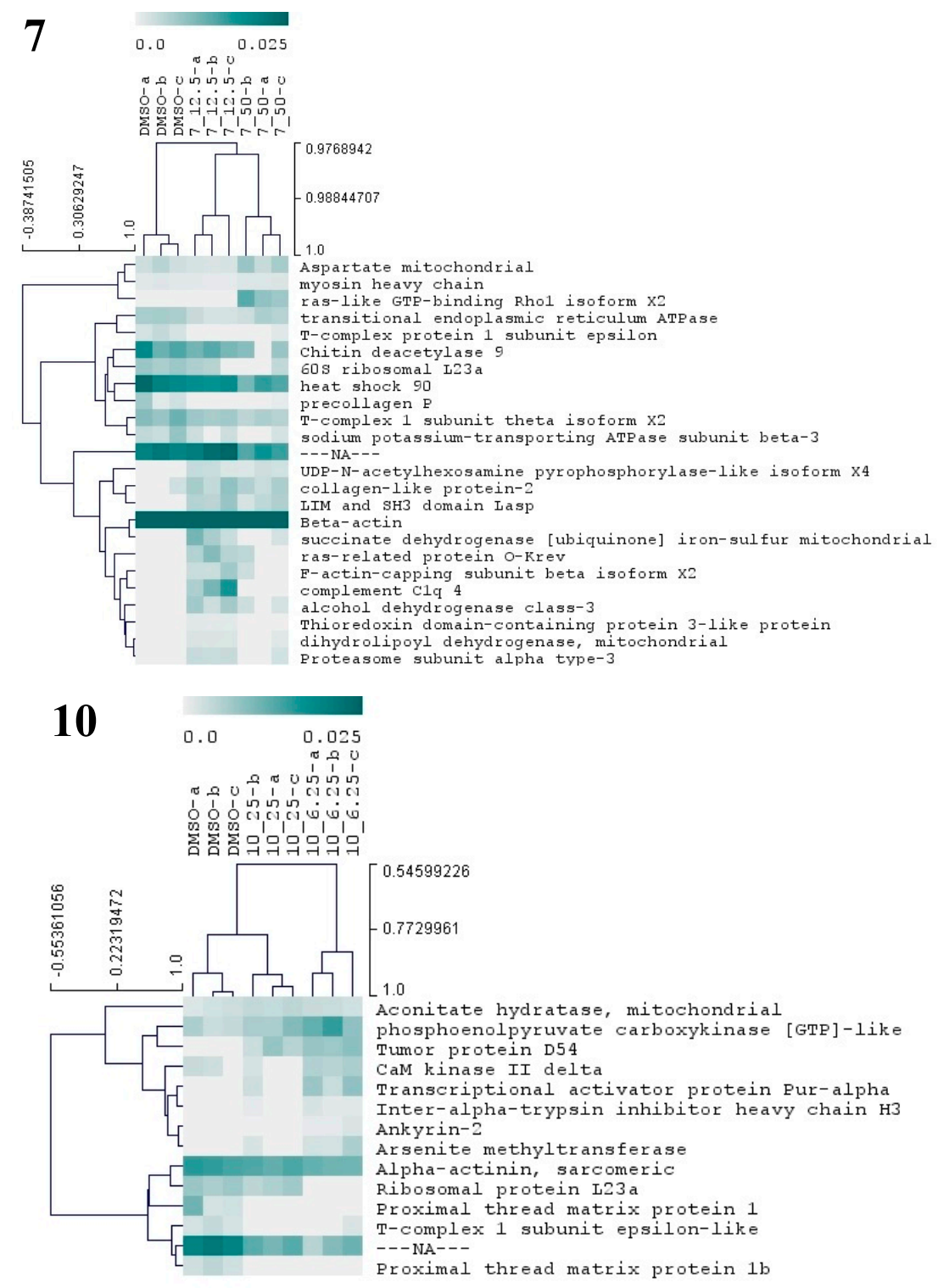

Figure 7. Cont. 


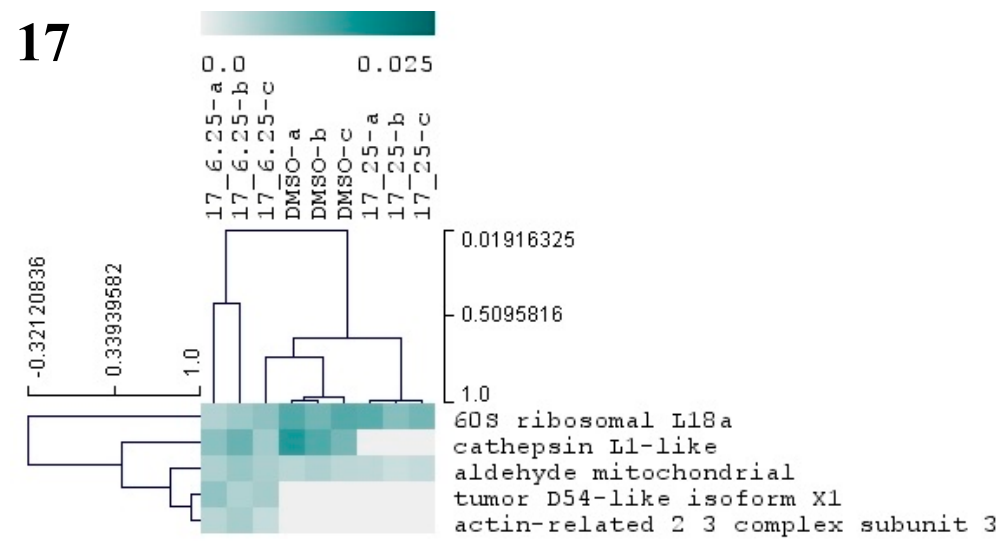

Figure 7. Hierarchical cluster analysis of the differential proteins from M. galloprovincialis larvae exposed to three different antifouling compounds, 7, 10, and 17. On the vertical axis of the dendrogram: clustering of proteins with similar abundance profiles. On the horizontal axis: grouping of samples with similar proteome. Only proteins with significant changes $(p<0.05)$ in abundance (based on NSAF values) are presented in the dendogram. The relative abundance values (NSAF) are represented in color gradient from 0.0 to 0.025 . Further information on NSAF values, significant $p$-values, and names of all differentially abundant proteins is included in Supplementary Table S2.

Exposure of larvae to compound 10 at 6.25 and $25 \mu \mathrm{M}$ resulted in the change of abundances in 14 proteins (Figure 7, Supplementary Table S1). Taking into consideration the molecular functions attributed to these proteins (Supplementary Figure S2) several cellular responses may be identified, elicited by 10, which include: alterations in cytoskeleton structure (Alpha-actinin, CaM kinase II, Ankyrin-2), in skeletal muscle function through modulation of $\mathrm{Ca}^{2+}$ transport and attachment of integral membrane proteins to cytoskeletal elements (CaM kinase II Ankyrin-2), energy metabolism (phosphoenolpyruvate carboxykinase and aconitate hydratase), gene transcription and translation (Ribosomal protein L23a, transcriptional activator protein Pur-alpha), and regulation of protein activity (tumor protein D54, T-complex 1 epsilon-like subunit). Other altered proteins are hypothetically involved in the transport of hyaluronan (inter-alpha-trypsin inhibitor heavy chain H3), a main component of the extracellular matrix and a key element in cell proliferation and migration, and xenobiotic detoxification processes (arsenite methyltransferase). Two putative proximal thread matrix proteins (TMPs) were clearly detected in the control group but become undetected in the two groups exposed to the compound 10, herein pointing to a significant drop in the expression of these proteins related to the activity of $\mathbf{1 0}$. TMPs are glycine-, tyrosine-, and asparagine-rich family of proteins carrying unique repeated sequence motifs. The proteins are specifically expressed by bivalve mollusks that adhere to underwater surfaces through the production of byssal threads. TMPs are thought to be localized throughout the byssal threads separating the collagenous microfibrils. Their function is to provide viscoelasticity to the byssal threads [52]. Hence, the inhibition of the two TMPs may be pointed as one of the most critical events underlying inhibition of larvae adhesion by compound $\mathbf{1 0 .}$

Exposure of plantigrade larvae to compound 17 at 6.25 and $25 \mu \mathrm{M}$ altered the abundance of five proteins (Figure 7, Supplementary Table S1). These proteins are known to be involved in major cellular metabolic processes as glycolysis/gluconeogenesis (mitochondrial aldehyde dehydrogenase), gene translation (60S ribosomal protein L18a), lysosomal protein degradation (cathepsin), or are constituents of the cytoskeleton (actin-related 2/3 complex subunit 3) (Figure 7, Supplementary Table S2). A homologous of the tumor protein D54 was detected in larvae exposed to 17 at $6.25 \mu \mathrm{M}$. With some of these constitutive proteins playing a role in basic metabolism and cellular functions, it is possible for this compound to affect the metabolism of a broad number of organism. 


\subsection{Non-Target Species Toxicity Assessment}

The marine ecotoxicity of compounds $4,5,7,10,15$, and 17 was studied regarding lethality to the brine shrimp, Artemia salina naupliids (Figure 8).

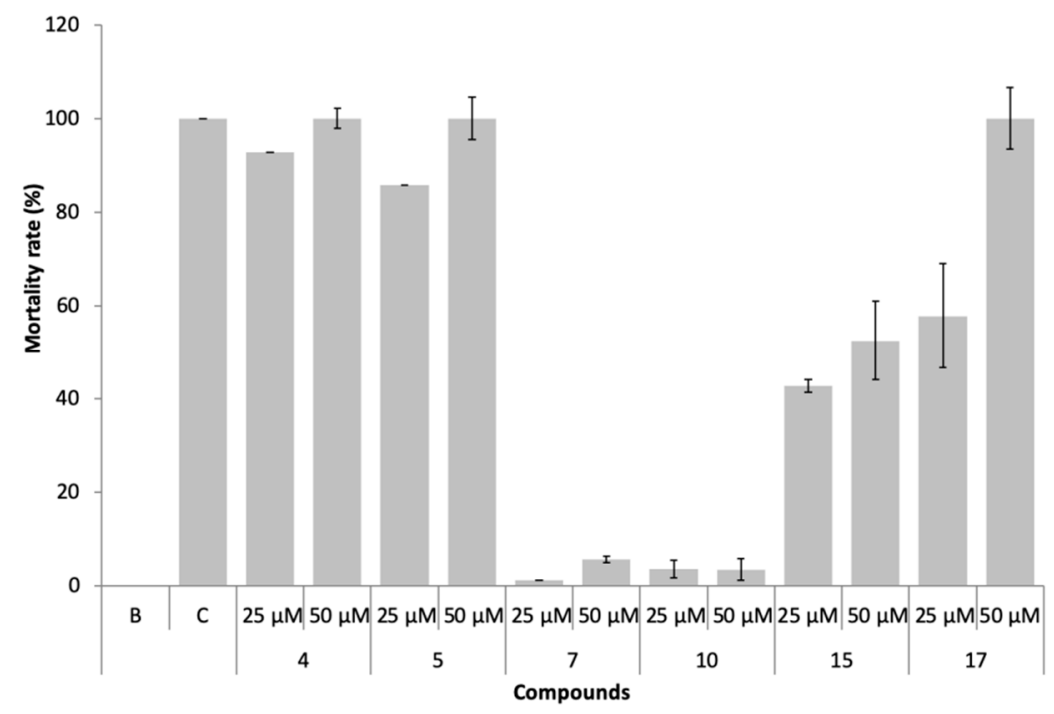

Figure 8. Mortality rate of Artemia salina exposed to the compounds 4, 5, 7, 10, 15, and 17 at 25 and $50 \mu \mathrm{M}$.

In the presence of compounds 7 and 10, non-toxic effects ( $<10 \%$ mortality) were observed, even at $50 \mu \mathrm{M}$. Compounds $4, \mathbf{5}, \mathbf{1 5}$, and 17 were found to be toxic (mortality $>10 \%$ ) to this non-target specie, particularly compounds 4 and 5 .

\section{Conclusions}

The marine industry is facing the phase-out of current persistent, bioaccumulative, and toxic biocides, shortening the available alternatives and creating a great opportunity for the development of new antifouling solutions. One strategy that has been exploited by researchers is the use of chemical defenses naturally employed by several marine organisms, which have been selected during evolution to have high specificity, high efficiency, and also be environmentally compatible inhibitors of biofouling. The synthesis of (bio)inspired antifoulants looks like a more sustainable way bringing an opportunity to produce commercial supplies for antifouling industry based on natural products. In this study, six synthetic xanthone derivatives showed antifouling potential regarding anti-settlement effectiveness and low toxicity to mussel larvae. The IUCN/SSC Invasive Species Specialist Group has listed M. galloprovincialis among the 100 "World's Worst" invaders, highlighting the worldwide relevance of studying the anti-settlement activity against this species. Concerning the mechanisms of action in mussel larvae, compounds 4 and 5 might be acting by the inhibition of AChE activity, while compounds $\mathbf{7}$ and $\mathbf{1 0}$ showed a specific target directly related with the production/constitution of byssal threads (expression of specific collagen proteins (PreCols) and proximal thread proteins (TMPs), respectively). Xanthones $\mathbf{7}$ and $\mathbf{1 0}$ also showed no toxicity ( $<10 \%$ mortality) to $A$. salina, being more suitable candidates to pursue biodegradability and deepen the ecotoxicological studies in the way to their inclusion in antifouling coatings. Also, the QSAR enables speeding the design of new potential active compounds and the synthesis of optimized xanthones with protonable amine groups in other positions is ongoing. In summary, adding to their previously known pharmacological actions, here we disclosed (thio)xanthonic derivatives as efficient antifoulants and brought new insights into their potentially specific mechanism of action related with adhesion. 
Supplementary Materials: The following are available online at http://www.mdpi.com/2218-273X/10/8/1126/s1, Table S1: NSAF values and Kruskal-wallis p-values of all differentially abundant proteins. Table S2: Blast search results with the tools blast2go and blastp from NCBI.

Author Contributions: Conceptualization, M.C.-d.-S.; design of the experimental work concerning the synthesis of xanthones, E.S. and M.P.; design of the experimental work concerning bioassays, J.R.A., I.C., and V.V.; compounds synthesis, E.S. and A.P.; virtual analysis, A.P.; in vivo antifouling bioassays, AChE and tyrosinase determinations and ecotoxicological bioassays, J.R.A., I.C., and M.F.; protein sample preparation, J.R.A. and A.C.; protein identification and quantification, A.C. and M.V.T.; protein data analyses, A.B.F.; writing-original draft preparation, J.R.A., M.C.-d.-S., and E.S.; writing-review and editing, J.R.A., M.C.-d.-S., E.S., A.P., I.C., A.C., M.V.T., M.P., V.V.; funding acquisition, J.R.A. and M.C.-d.-S. All authors have read and agreed to the published version of the manuscript.

Funding: This research was supported by national funds through FCT-Foundation for Science and Technology within the scope of UIDB/04423/2020 and UIDP/04423/2020 and under the project PTDC/AAG-TEC/0739/2014 (reference POCI-01-0145-FEDER-016793) supported through national funds provided by FCT and ERDF-European Regional Development Fund through the COMPETE—Programa Operacional Factores de Competitividade (POFC) programme and RIDTI-Reforçar a Investigação, o Desenvolvimento Tecnológico e a Inovação (project 9471) and the project NASCEM PTDC/BTA-BTA/31422/2017 (POCI-01-0145-FEDER-031422) also financed by FCT, COMPETE2020 and PORTUGAL2020.

Conflicts of Interest: The authors declare no conflict of interest.

\section{References}

1. Antunes, J.; Leao, P.; Vasconcelos, V. Marine biofilms: Diversity of communities and of chemical cues. Environ. Microbiol. Rep. 2019, 11, 287-305. [CrossRef]

2. Parrino, B.; Schillaci, D.; Carnevale, I.; Giovannetti, E.; Diana, P.; Cirrincione, G.; Cascioferro, S. Synthetic small molecules as anti-biofilm agents in the struggle against antibiotic resistance. Eur. J. Med. Chem. 2019, 161, 154-178. [CrossRef]

3. Hadfield, M.G. Biofilms and Marine Invertebrate Larvae: What Bacteria Produce That Larvae Use to Choose Settlement Sites. Annu. Rev. Mar. Sci. 2011, 3, 453-470. [CrossRef] [PubMed]

4. Schultz, M.P.; Bendick, J.A.; Holm, E.R.; Hertel, W.M. Economic impact of biofouling on a naval surface ship. Biofouling 2011, 27, 87-98. [CrossRef] [PubMed]

5. Galil, B.S.; McKenzie, C.; Bailey, S.; Campbell, M.; Davidson, I.; Drake, L.; Hewitt, C.; Occhipinti-Ambrogi, A.; Piola, R. ICES Viewpoint background document: Evaluating and mitigating introduction of marine non-native species via vessel bio- fouling. ICES Ad Hoc Rep. 2019, 2019, 17.

6. Thomas, K.V.; Brooks, S. The environmental fate and effects of antifouling paint biocides. Biofouling 2010, 26, 73-88. [CrossRef] [PubMed]

7. Jung, S.M.; Bae, J.S.; Kang, S.G.; Son, J.S.; Jeon, J.H.; Lee, H.J.; Jeon, J.Y.; Sidharthan, M.; Ryu, S.H.; Shin, H.W. Acute toxicity of organic antifouling biocides to phytoplankton Nitzschia pungens and zooplankton Artemia larvae. Mar. Pollut. Bull. 2017, 124, 811-818. [CrossRef] [PubMed]

8. Almeida, J.R.; Vasconcelos, V. Natural antifouling compounds: Effectiveness in preventing invertebrate settlement and adhesion. Biotechnol. Adv. 2015, 33, 343-357. [CrossRef]

9. Qian, P.-Y.; Li, Z.; Xu, Y.; Li, Y.; Fusetani, N. Mini-review: Marine natural products and their synthetic analogs as antifouling compounds: 2009-2014. Biofouling 2015, 31, 101-122. [CrossRef]

10. Wang, K.L.; Wu, Z.H.; Wang, Y.; Wang, C.Y.; Xu, Y. Mini-Review: Antifouling Natural Products from Marine Microorganisms and Their Synthetic Analogs. Mar. Drugs 2017, 15, 266. [CrossRef]

11. Qi, S.-H.; Ma, X. Antifouling Compounds from Marine Invertebrates. Mar. Drugs 2017, 15, 263.

12. Pinto, M.M.; Sousa, M.E.; Nascimento, M.S. Xanthone derivatives: New insights in biological activities. Curr. Med. Chem. 2005, 12, 2517-2538. [CrossRef] [PubMed]

13. Sun, R.R.; Miao, F.P.; Zhang, J.; Wang, G.; Yin, X.L.; Ji, N.Y. Three new xanthone derivatives from an algicolous isolate of Aspergillus wentii. Magn. Reson. Chem. 2013, 51, 65-68. [CrossRef] [PubMed]

14. Li, Y.-X.; Wu, H.-X.; Xu, Y.; Shao, C.-L.; Wang, C.-Y.; Qian, P.-Y. Antifouling Activity of Secondary Metabolites Isolated from Chinese Marine Organisms. Mar. Biotechnol. 2013, 15, 552-558. [CrossRef]

15. Nong, X.H.; Zhang, X.Y.; Xu, X.Y.; Qi, S.H. Antifouling Compounds from the Marine-Derived Fungus Aspergillus terreus SCSGAF0162. Nat. Prod. Commun. 2015, 10, 1033-1034. [CrossRef]

16. Chen, L.; Qian, P.Y. Review on Molecular Mechanisms of Antifouling Compounds: An Update since 2012. Mar. Drugs 2017, 15, 264. [CrossRef] 
17. Zhang, Y.F.; Zhang, H.M.; He, L.S.; Liu, C.D.; Xu, Y.; Qian, P.Y. Butenolide Inhibits Marine Fouling by Altering the Primary Metabolism of Three Target Organisms. ACS Chem. Biol. 2012, 7, 1049-1058. [CrossRef]

18. Almeida, J.R.; Correia-da-Silva, M.; Sousa, E.; Antunes, J.; Pinto, M.; Vasconcelos, V.; Cunha, I. Antifouling potential of Nature-inspired sulfated compounds. Sci. Rep. 2017, 7, 42424. [CrossRef]

19. Almeida, J.R.; Moreira, J.; Pereira, D.; Pereira, S.; Antunes, J.; Palmeira, A.; Vasconcelos, V.; Pinto, M.; Correia-da-Silva, M.; Cidade, H. Potential of synthetic chalcone derivatives to prevent marine biofouling. Sci. Total Environ. 2018, 643, 98-106. [CrossRef]

20. Neves, A.R.; Almeida, J.R.; Carvalhal, F.; Camara, A.; Pereira, S.; Antunes, J.; Vasconcelos, V.; Pinto, M.; Silva, E.R.; Sousa, E.; et al. Overcoming environmental problems of biocides: Synthetic bile acid derivatives as a sustainable alternative. Ecotoxicol. Environ. Saf. 2020, 187, 109812. [CrossRef]

21. Costa, E.; Sousa, E.; Nazareth, N.; Nascimento, M.S.J.; Pinto, M.M.M. Synthesis of Xanthones and Benzophenones as Inhibitors of Tumor Cell Growth. Lett. Drug Des. Discov. 2010, 7, 487-493. [CrossRef]

22. Pedro, M.; Cerqueira, F.; Sousa, M.E.; Nascimento, M.S.J.; Pinto, M. Xanthones as inhibitors of growth of human cancer cell lines and their effects on the proliferation of human lymphocytes in vitro. Bioorgan. Med. Chem. 2002, 10, 3725-3730. [CrossRef]

23. Paiva, A.M.; Sousa, M.E.; Camoes, A.; Nascimento, M.S.J.; Pinto, M.M.M. Prenylated xanthones: Antiproliferative effects and enhancement of the growth inhibitory action of 4-hydroxytamoxifen in estrogen receptor-positive breast cancer cell line. Med. Chem. Res. 2012, 21, 552-558. [CrossRef]

24. Sousa, E.P.; Silva, A.M.S.; Pinto, M.M.M.; Pedro, M.M.; Cerqueira, F.A.M.; Nascimento, M.S.J. Isomeric kielcorins and dihydroxyxanthones: Synthesis, structure elucidation, and inhibitory activities of growth of human cancer cell lines and on the proliferation of human lymphocytes in vitro. Helv. Chim. Acta 2002, 85, 2862-2876. [CrossRef]

25. Palmeira, A.; Vasconcelos, M.H.; Paiva, A.; Fernandes, M.X.; Pinto, M.; Sousa, E. Dual inhibitors of P-glycoprotein and tumor cell growth: (Re)discovering thioxanthones. Biochem. Pharmacol. 2012, 83, 57-68. [CrossRef] [PubMed]

26. Almeida, J.; Freitas, M.; Cruz, S.; Leão, P.; Vasconcelos, V.; Cunha, I. Acetylcholinesterase in biofouling species: Characterization and mode of action of cyanobacteria-derived antifouling agents. Toxins 2015, 7, 2739. [CrossRef]

27. Ellman, G.L.; Courtney, K.D.; Andres, V., Jr.; Featherstone, R.M. A new and rapid colorimetric determination of acetylcholinesterase activity. Biochem. Pharmacol. 1961, 7, 88-95. [CrossRef]

28. Adhikari, A.; Devkota, H.P.; Takano, A.; Masuda, K.; Nakane, T.; Basnet, P.; Skalko-Basnet, N. Screening of Nepalese crude drugs traditionally used to treat hyperpigmentation: In vitro tyrosinase inhibition. Int. J. Cosmet. Sci. 2008, 30, 353-360. [CrossRef]

29. Trepos, R.; Cervin, G.; Hellio, C.; Pavia, H.; Stensen, W.; Stensvag, K.; Svendsen, J.S.; Haug, T.; Svenson, J. Antifouling compounds from the sub-arctic ascidian Synoicum pulmonaria: Synoxazolidinones A and C, pulmonarins A and B, and synthetic analogues. J. Nat. Prod. 2014, 77, 2105-2113. [CrossRef]

30. Martin-Rodriguez, A.J.; Babarro, J.M.; Lahoz, F.; Sanson, M.; Martin, V.S.; Norte, M.; Fernandez, J.J. From broad-spectrum biocides to quorum sensing disruptors and mussel repellents: Antifouling profile of alkyl triphenylphosphonium salts. PLoS ONE 2015, 10, e0123652. [CrossRef]

31. Campos, A.; Danielsson, G.; Farinha, A.P.; Kuruvilla, J.; Warholm, P.; Cristobal, S. Shotgun proteomics to unravel marine mussel (Mytilus edulis) response to long-term exposure to low salinity and propranolol in a Baltic Sea microcosm. J. Proteom. 2016, 137, 97-106. [CrossRef]

32. Wisniewski, J.R.; Zougman, A.; Nagaraj, N.; Mann, M. Universal sample preparation method for proteome analysis. Nat. Meth. 2009, 6, 359-362. [CrossRef] [PubMed]

33. Meyer, B.N.; Ferrigni, N.R.; Putnam, J.E.; Jacobsen, L.B.; Nichols, D.E.; McLaughlin, J.L. Brine shrimp: A convenient general bioassay for active plant constituents. Planta Medica 1982, 45, 31-34. [CrossRef]

34. Saeed, A.I.; Sharov, V.; White, J.; Li, J.; Liang, W.; Bhagabati, N.; Braisted, J.; Klapa, M.; Currier, T.; Thiagarajan, M.; et al. TM4: A free, open-source system for microarray data management and analysis. Biotechniques 2003, 34, 374-378. [CrossRef] [PubMed]

35. Dudek, A.Z.; Arodz, T.; Galvez, J. Computational methods in developing quantitative structure-activity relationships (QSAR): A review. Comb. Chem. High Throughput Screen. 2006, 9, 213-228. [CrossRef] [PubMed] 
36. Golbraikh, A.; Shen, M.; Xiao, Z.; Xiao, Y.-D.; Lee, K.-H.; Tropsha, A. Rational selection of training and test sets for the development of validated QSAR models. J. Comput. Aided Mol. Des. 2003, 17, 241-253. [CrossRef] [PubMed]

37. Roy, K.; Kar, S.; Das, R.N. Understanding the Basics of QSAR for Applications in Pharmaceutical Sciences and Risk Assessment; Academic Press: Boston, MA, USA, 2015; pp. 47-150.

38. Raychaudhury, C.; Ray, S.K.; Ghosh, J.J.; Roy, A.B.; Basak, S.C. Discrimination of isomeric structures using information theoretic topological indices. J. Comput. Chem. 1984, 5, 581-588. [CrossRef]

39. Todeschini, R.; Consonni, V. Handbook of Molecular Descriptors. In Methods and Principles in Medicinal Chemistry Series; Wiley-VCH: Weinheim, Germany, 2000; Volume 11, pp. 45-65.

40. Lu, S.H.; Wu, J.W.; Liu, H.L.; Zhao, J.H.; Liu, K.T.; Chuang, C.K.; Lin, H.Y.; Tsai, W.B.; Ho, Y. The discovery of potential acetylcholinesterase inhibitors: A combination of pharmacophore modeling, virtual screening, and molecular docking studies. J. Biomed. Sci. 2011, 18, 8. [CrossRef]

41. Johnson, G.; Moore, S.W. The peripheral anionic site of acetylcholinesterase: Structure, functions and potential role in rational drug design. Curr. Pharm. Des. 2006, 12, 217-225. [CrossRef]

42. Bourne, Y.; Taylor, P.; Radic, Z.; Marchot, P. Structural insights into ligand interactions at the acetylcholinesterase peripheral anionic site. EMBO J. 2003, 22, 1-12. [CrossRef]

43. Mallender, W.D.; Szegletes, T.; Rosenberry, T.L. Acetylthiocholine binds to asp74 at the peripheral site of human acetylcholinesterase as the first step in the catalytic pathway. Biochemistry 2000, 39, 7753-7763. [CrossRef] [PubMed]

44. Ordentlich, A.; Barak, D.; Kronman, C.; Ariel, N.; Segall, Y.; Velan, B.; Shafferman, A. Functional characteristics of the oxyanion hole in human acetylcholinesterase. J. Biol. Chem. 1998, 273, 19509-19517. [CrossRef] [PubMed]

45. Bennion, B.J.; Essiz, S.G.; Lau, E.Y.; Fattebert, J.L.; Emigh, A.; Lightstone, F.C. A wrench in the works of human acetylcholinesterase: Soman induced conformational changes revealed by molecular dynamics simulations. PLoS ONE 2015, 10, e0121092. [CrossRef] [PubMed]

46. Varadaraju, K.R.; Kumar, J.R.; Mallesha, L.; Muruli, A.; Mohana, K.N.; Mukunda, C.K.; Sharanaiah, U. Virtual screening and biological evaluation of piperazine derivatives as human acetylcholinesterase inhibitors. Int. J. Alzheimer's Dis. 2013, 2013, 653962. [CrossRef]

47. Dvir, H.; Silman, I.; Harel, M.; Rosenberry, T.L.; Sussman, J.L. Acetylcholinesterase: From 3D structure to function. Chem. Biol. Interact. 2010, 187, 10-22. [CrossRef]

48. Saxena, A.; Qian, N.; Kovach, I.M.; Kozikowski, A.P.; Pang, Y.P.; Vellom, D.C.; Radic, Z.; Quinn, D.; Taylor, P.; Doctor, B.P. Identification of amino acid residues involved in the binding of Huperzine A to cholinesterases. Protein Sci. A Publ. Protein Soc. 1994, 3, 1770-1778. [CrossRef]

49. Bourne, Y.; Kolb, H.C.; Radic, Z.; Sharpless, K.B.; Taylor, P.; Marchot, P. Freeze-frame inhibitor captures acetylcholinesterase in a unique conformation. Proc. Natl. Acad. Sci. USA 2004, 101, 1449-1454. [CrossRef]

50. Hornberg, A.; Artursson, E.; Warme, R.; Pang, Y.P.; Ekstrom, F. Crystal structures of oxime-bound fenamiphos-acetylcholinesterases: Reactivation involving flipping of the His447 ring to form a reactive Glu334-His447-oxime triad. Biochem. Pharm. 2010, 79, 507-515. [CrossRef]

51. Bayer, M.; Hellio, C.; Marechal, J.P.; Frank, W.; Lin, W.H.; Weber, H.; Proksch, P. Antifouling Bastadin Congeners Target Mussel Phenoloxidase and Complex Copper(II) Ions. Mar. Biotechnol. 2011, 13, 1148-1158. [CrossRef]

52. Sagert, J.; Waite, J.H. Hyperunstable matrix proteins in the byssus of Mytilus galloprovincialis. J. Exp. Biol. 2009, 212, 2224-2236. [CrossRef]

(C) 2020 by the authors. Licensee MDPI, Basel, Switzerland. This article is an open access article distributed under the terms and conditions of the Creative Commons Attribution (CC BY) license (http://creativecommons.org/licenses/by/4.0/). 